\title{
Perinatal mental distress and infant morbidity in Ethiopia: a cohort study
}

\author{
Joanna Ross, ${ }^{1}$ Charlotte Hanlon, ${ }^{2,3}$ Girmay Medhin, ${ }^{4}$ Atalay Alem, ${ }^{3}$ Fikru Tesfaye, ${ }^{5}$ \\ Bogale Worku, ${ }^{6}$ Michael Dewey, ${ }^{2}$ Vikram Patel, ${ }^{1,7}$ Martin Prince $^{2}$
}

\begin{abstract}
- Two supplementary tables are published online only. To view these files please visit the journal online (http://adc bmj.com)
\end{abstract}

${ }^{1}$ London School of Hygiene and Tropical Medicine, London, UK

${ }^{2}$ King's College London,

Institute of Psychiatry, Health

Service and Population

Research Department,

London, UK

${ }^{3}$ Department of Psychiatry, Addis Ababa University, Addis

Ababa, Ethiopia

${ }^{4}$ Aklilu-Lemma Institute of

Pathobiology, Addis Ababa

University, Addis Ababa,

Ethiopia

${ }^{5}$ School of Public Health,

Addis Ababa University, Addis

Ababa, Ethiopia

${ }^{6}$ Department of Paediatrics and Child Health, Addis Ababa University, Faculty of Medicine, Addis Ababa, Ethiopia

${ }^{7}$ Sangath Centre, Mapusa, Goa, India

\section{Correspondence to}

Dr Charlotte Hanlon, Faculty of Medicine, Department of Psychiatry, P0 Box 9086, Addis Ababa University, Addis Ababa, Ethiopia;

charlotte.hanlon@kcl.ac.uk

Accepted 17 May 2010 Published Online First 28 July 2010

\begin{abstract} common mental disorders (CMD) in Ethiopia on the risk of key illnesses of early infancy: diarrhoea, fever and acute respiratory illnesses (ARI) and (2) to behaviours.

Design Population-based cohort study.

Setting Demographic surveillance site in a predominantly rural area of Ethiopia.
\end{abstract}

Objectives (1) To investigate the impact of perinatal explore the potential mediating role of maternal health

Participants 1065 women (86.3\% of eligible) in the third trimester of pregnancy were recruited and 954 (98.6\%) of surviving, singleton mother-infant pairs were followed up until 2 months after birth.

Main exposure measure High levels of CMD symptoms, as measured by the locally validated SelfReporting Questionnaire (SRO-20 $\geq 6$ ), in pregnancy only, postnatally only and at both time-points ('persistent').

Main outcome measures Maternal report of infant illness episodes in first 2 months of life.

Results The percentages of infants reported to have experienced diarrhoea, ARI and fever were $26.0 \%$, $25.0 \%$ and $35.1 \%$, respectively. Persistent perinatal CMD symptoms were associated with 2.15 times $195 \% \mathrm{Cl}$ 1.39 to 3.34 ) increased risk of infant diarrhoea in a fully adjusted model. The strength of association was not affected by including potential mediators: breast feeding practices, hygiene, the infant's vaccination status or impaired maternal functioning. Persistent perinatal CMD was not associated with infant $A R I$ or fever after adjusting for confounders.

Conclusions Persistent perinatal CMD was associated with infant diarrhoea in this low-income country setting. The observed relationship was independent of maternal health-promoting practices. Future research should further explore the mechanisms underlying the observed association to inform intervention strategies.

\section{BACKGROUND}

Maternal common mental disorders (CMD), characterised by depressive, anxiety and somatic symptoms, have been associated with poorer infant outcomes. In high-income settings, infants of women with postnatal CMD are more likely to have impaired cognitive, social and emotional development. ${ }^{1-3}$ Maternal health behaviours on behalf of their infants may also be negatively affected by maternal CMD: decreased vaccination, impaired child safety behaviours ${ }^{4}$ and increased use of emergency ${ }^{5-7}$ rather than preventive services. $^{7}$

\section{What is already known on this topic}

- In Pakistan, maternal depression was associated with an increased RR of 2.3 (95\% Cl 1.6 to 3.1 ) of $\geq 5$ infant diarrhoeal episodes.

- Maternal common mental disorder symptoms adversely affect health behaviours, for example, breast feeding and taking a child for vaccination.

\section{What this study adds}

- An association between maternal perinatal common mental disorder (CMD) and infant diarrhoea was found.

- Impairment of maternal health-promoting behaviours did not appear to mediate the association between maternal perinatal CMD and infant diarrhoea.

- Maternal perinatal CMD symptoms were not associated with infant acute respiratory illness or fever in Ethiopia.

The prevalence of maternal CMD varies across low- and middle-income countries (LAMICs) ${ }^{8}$ : from $6.1 \%$ in Uganda ${ }^{9}$ to $34.5 \%$ in South Africa. ${ }^{10}$ Maternal CMD has been associated with low birth weight in some, ${ }^{11-13}$ although not all, ${ }^{14}$ LAMIC settings and a range of adverse infant outcomes: undernutrition, ${ }^{15-20}$ poorer cognitive development, ${ }^{16}$ child injury ${ }^{21}$ and increased diarrhoeal illness. ${ }^{22-24}$ In Pakistan, ${ }^{23}$ infants of mothers with postnatal depression had 2.3 times the odds of having five or more diarrhoeal episodes in their first year, after adjusting for confounders. Studies from Chile ${ }^{22}$ and Nigeria ${ }^{18}$ found similar associations with infant diarrhoeal episodes and other illnesses, although neither study adjusted for confounders. Possible mechanisms underlying the association have been postulated ${ }^{24}$ although not investigated systematically.

In this paper, we present findings from a population-based cohort, the Perinatal Maternal Mental Disorder in Ethiopia study. This study evaluated the impact of perinatal CMD upon infant episodes of diarrhoea, acute respiratory illnesses (ARI) and 
fever and explored the potential mediating role of maternal health behaviours.

\section{METHODS}

\section{Study design}

This was a population-based cohort study.

\section{Study site}

The study was located in the Demographic Surveillance Site (DSS) at the Butajira Rural Health Programme (BRHP), Ethiopia. ${ }^{25}$ The area is predominantly rural, with one town, and located $130 \mathrm{~km}$ south of the capital city, Addis Ababa. Infant illness episodes are commonplace: in a recent national survey, $14 \%$ of infants had ARI, $17 \%$ had fever and $14 \%$ had diarrhoea in the preceding 2 weeks. ${ }^{26}$

\section{Participants and data collection}

Eligible women were between 15 and 49 years of age, able to speak Amharic (the official language of Ethiopia), living in the DSS and in the third trimester of pregnancy between July 2005 and February 2006. Women were identified by BRHP enumerators and, after giving informed consent, were interviewed. The project data collectors were local women with completed high school education who had been trained for a minimum of 1 week. They administered questionnaires covering all pregnancy and postnatal variables as well as carrying out anthropometric measurements. Data were checked in the field and double-entered on the same day in most instances. Missing data or discrepancies were resolved by revisiting the women within 1 week. Quality was maintained through field checks by supervisors and project co-ordinators, supported by regular project meetings.

\section{Main exposure measure}

Perinatal CMD was measured at recruitment using the SelfReporting Questionnaire (SRQ-20). ${ }^{27}$ This 20 -item scale asks about CMD symptoms present in the preceding month and generates a continuously distributed scale score. The SRQ-20 was extensively prevalidated in a mixed sample of pregnant and postnatal women in Butajira. ${ }^{28}$ On the basis of our validation study, high levels of CMD symptoms were defined as a score of $\geq 6$ on the SRQ-20. ${ }^{28}$ CMD exposure categories were defined as follows: neither pregnancy nor postnatal, pregnancy only, postnatal only, and both pregnancy and postnatal ('persistent'). The perinatal period was defined according to convention within the mental health literature, ranging from the third trimester of pregnancy to 3 months after birth. ${ }^{29}$ In this study, the median postnatal time-point was 59 days.

\section{Outcome measures}

Outcome measures were infant illness episodes since birth as reported by the mother at the 2 months postnatal time-point: (1) diarrhoea: defined as three or more loose or fluid stools in a $24 \mathrm{~h}$ period, (2) ARI: defined as cough with associated difficulty breathing, and (3) fever.

\section{Potential confounders}

\section{Maternal characteristics}

Maternal autonomy was defined according to whether the woman had to ask her husband before selling crops, spending household money, attending groups, buying medication or attending a health facility. Responses were summed and categorised into women who always had to ask, those who sometimes had to ask and those who did not have to ask at all. Parity included birth of the project child.

\section{Parental educational level}

Parental educational level was determined according to maternal report.

\section{Socio-economic status}

Socio-economic status was defined according to hunger experienced by the mother in the preceding month due to lack of resources, subjective wealth relative to others, indebtedness and lack of emergency resources.

\section{Environmental conditions}

Environmental conditions encompassed water supply, sanitation, disposal of rubbish, having a window, animals in the house at night, urban or rural residence and number of children under 5 years.

\section{Maternal substance use and maternal health}

Maternal substance use and maternal health were defined according to self-report data on substance use (alcohol, khat) and episodes of diarrhoea, fever and malaria since birth. Maternal weight and height were measured using standard anthropometric techniques ${ }^{30}$ and used to calculate body mass index $(\mathrm{BMI})\left(\mathrm{kg} / \mathrm{m}^{2}\right)$.

\section{Infant characteristics}

Infant gender was recorded at birth. In six of nine rural subdistricts, birth weight was measured using a seca 725 scales (accurate to $10 \mathrm{~g}$ ) (seca, Hamburg, Germany). Birth weights were obtained within $48 \mathrm{~h}$ for the infants of 521 (79.7\%) women living in the selected subdistricts. ${ }^{14}$

\section{Social support}

Social support was determined according to self-report of frequency of contact with friends, adequacy of help received with home and children, and support received from the woman's family and husband.

\section{Potential mediators}

Time to initiation of breast feeding was categorised as: within an hour of birth, 1-8 h, between 8 and $24 \mathrm{~h}$ and longer than $24 \mathrm{~h}$. This assessment took place a median of 2 days after birth. At 2 months after birth, women were asked about frequency of soap use, non-exclusive breast feeding and the infant's vaccination status (checked against the vaccination record). The WHO Disability Assessment Schedule II, ${ }^{31}$ as previously used in Ethiopia, ${ }^{32}$ was used to determine the number of days in the preceding month that the woman was unable to perform her usual activities.

\section{Statistical methods}

Associations between CMD exposure categories and potential confounders were explored by calculating incidence RR with $95 \%$ CI. RRs were estimated using a Poisson working model and sandwich estimators of the standard errors. ${ }^{33}$ Multivariable analyses were conducted, initially adding groups of potential confounders and noting changes in the estimated RR for maternal CMD and infant illness episode. Subsequently all confounders, except maternal BMI, were added simultaneously to obtain the final adjusted RR. BMI was only available for $80.1 \%$ of women and so analyses were repeated with BMI included and both models presented. Potential mediators 
were added to the fully adjusted model, one at a time, and any changes in the RR estimate were noted. Stata version $10.1^{34}$ was used for data analysis.

\section{RESULTS}

Of the 1065 women recruited in pregnancy, 1006 had singleton live births (see figure 1). At the 2 -month postnatal time-point, 954 (98.6\%) of surviving mother-infant pairs were assessed.

The percentages of infants reported to have experienced episodes of diarrhoea, ARI and fever since birth were $26.0 \%$, $25.0 \%$ and $35.1 \%$, respectively. Almost half (47.2\%) of the infants did not experience any of the conditions, and $6.8 \%$ experienced all three.

The majority of women (86.2\%) did not experience high levels of CMD symptoms in pregnancy or during the postnatal period. Of those women with CMD symptoms, 88 (9.2\%) had high CMD in pregnancy only, $20(2.1 \%)$ in the postnatal period only and $24(2.5 \%)$ had persistent perinatal CMD.

The crude RR for the associations between potential confounding variables and infant diarrhoea, ARI and fever are shown in table 1.

\section{Perinatal CMD symptoms and infant diarrhoea}

The presence of high CMD symptoms in the postnatal period only or during both pregnancy and the postnatal period was significantly associated with an increased crude risk of infant diarrhoea: RR 1.84 (95\% CI 1.12 to 3.03) and RR 2.90 (95\% CI 2.18 to 3.85$)$, respectively. CMD symptoms during pregnancy

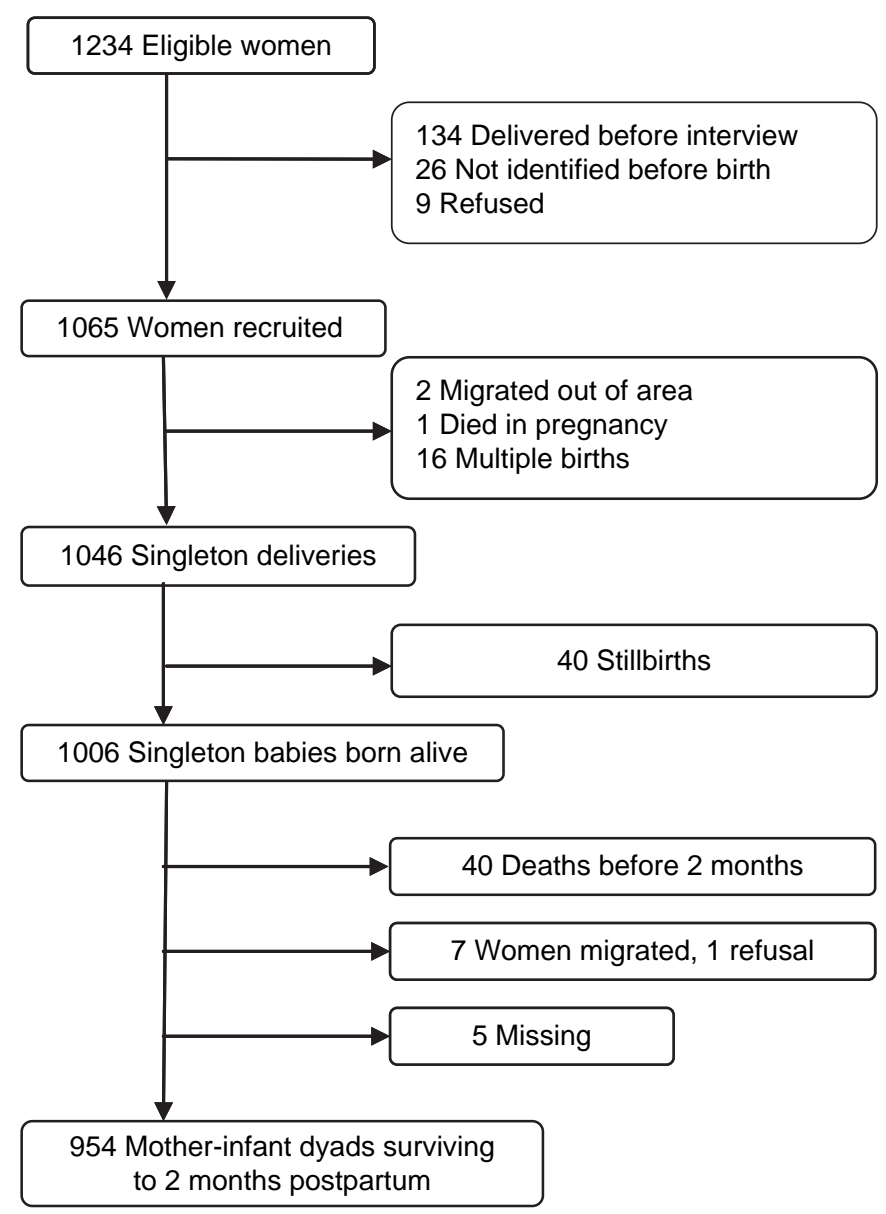

Figure 1 Flow chart of surviving mother-infant dyads assessed 2 months after birth. alone were not significantly associated with increased risk of infant diarrhoea.

Individual groups of potential confounders were added into the model and the resulting changes to the $R R$ for maternal $\mathrm{CMD}$ and infant diarrhoea were recorded (table 2).

$\mathrm{CMD}$ in the postnatal period only was associated with increased risk of infant diarrhoea except when adjusting for socio-economic status and maternal health. The association between persistent CMD and infant diarrhoea was significant for all separate groups of confounders.

When all potential confounders were adjusted for simultaneously (excluding maternal BMI), persistent maternal CMD symptoms continued to be associated with increased risk of infant diarrhoea (RR 2.15; 95\% CI 1.39 to 3.34). The effect of CMD symptoms in the postnatal period alone was no longer significant. Including maternal BMI as a potential confounder led to an increase in the strength of association.

When potential mediating variables were added into the equation, there was little or no change in the strength of association between maternal CMD and infant diarrhoea.

\section{Perinatal CMD symptoms and infant ARI and fever}

Persistent CMD symptoms also appeared to increase the risk of both ARI (crude RR 2.24; 95\% CI 1.52 to 3.30) and fever (crude RR 1.61; 95\% CI 1.10 to 2.35), although CMD in pregnancy or in the postnatal period alone were not significantly associated with either ARI or fever (see table 3). However, these associations were confounded by socio-economic status and maternal ill-health and were no longer significant in the final fully adjusted models. As with the outcome of infant diarrhoea, addition of potential mediators did not affect the size of the association between CMD and ARI or fever (see online tables 1 and 2).

\section{DISCUSSION}

This paper extends the growing body of literature from Pakistan, Chile and Nigeria linking poor maternal mental health to increased risk of infant illness. ${ }^{18} 2223$ In this study, persistent perinatal CMD symptoms were associated with more than double the risk of an infant diarrhoeal episode during the first 2 months of life. However, this association was not mediated by a negative impact of $\mathrm{CMD}$ on maternal health-promoting behaviours. No association was found between perinatal CMD and infant ARI or fever after adjusting for potential confounders.

Only when maternal CMD symptoms were persistent was a significant association with infant diarrhoeal episodes observed. We might have expected CMD symptoms with onset in the postnatal period ('postnatal only') to have also been associated with infant diarrhoeal episodes. Such an association was observed in the crude analyses and only decreased when adjusting for maternal physical ill-health and socioeconomic status. A major limitation of our study was the small number of women with high levels of postnatal CMD symptoms, raising the possibility that we were under-powered to detect a true association. A further limitation arose from our reliance upon self-report of maternal ill-health simultaneously with measurement of postnatal CMD. Both negative recall bias and somatic expression of mental distress could have resulted in women with higher CMD symptoms being more likely to report somatic complaints irrespective of their true health status, leading to over-adjustment for maternal physical ill-health. This explanation is supported by the finding that inclusion of 
Table 1 RR for association between potential explanatory variables and the outcomes of infant diarrhoea, acute respiratory illness and fever in the first 2 months of life

\begin{tabular}{|c|c|c|c|c|}
\hline & $\mathbf{N}(\%)$ & Diarrhoea RR (95\% CI) & ARI RR (95\% CI) & Fever RR $(95 \%$ CI) \\
\hline \multicolumn{5}{|l|}{ Maternal characteristics } \\
\hline Age (years), mean (SD) & $26.9(6.3)$ & $1.02(1.00$ to 1.04$)$ & 0.99 (0.98 to 1.01$)$ & $1.00(0.99$ to 1.01$)$ \\
\hline \multicolumn{5}{|l|}{ Parity } \\
\hline Primiparous & $138(14.5)$ & Reference & Reference & Reference \\
\hline 2-4 Births & $423(44.3)$ & $1.42(0.96$ to 2.10$)$ & $1.06(0.77$ to 1.47$)$ & $0.69(0.54$ to 0.87$)$ \\
\hline 5 Or more births & $393(41.2)$ & $1.60(1.09$ to 2.36$)$ & $0.89(0.64$ to 1.25$)$ & $0.83(0.66$ to 1.05$)$ \\
\hline \multicolumn{5}{|l|}{ Level of autonomy $(n=947)$} \\
\hline Always asks & $613(64.7)$ & Reference & Reference & Reference \\
\hline Sometimes ask & $189(20.0)$ & $1.23(0.95$ to 1.58$)$ & $1.09(0.83$ to 1.42$)$ & $0.85(0.67$ to 1.08$)$ \\
\hline Doesn't have to ask & $145(15.3)$ & $0.87(0.62$ to 1.21$)$ & $0.82(0.58$ to 1.16$)$ & $0.92(0.72$ to 1.19$)$ \\
\hline \multicolumn{5}{|l|}{ No formal education } \\
\hline Mother & $763(80.0)$ & $1.30(0.97$ to 1.76$)$ & $1.10(0.83$ to 1.47$)$ & $1.25(0.98$ to 1.58$)$ \\
\hline Husband $(n=947)$ & $349(36.9)$ & $1.15(0.92$ to 1.42$)$ & $1.19(0.95$ to 1.48$)$ & $1.11(0.93$ to 1.32$)$ \\
\hline \multicolumn{5}{|l|}{ Socio-economic status } \\
\hline Lower wealth $(\mathrm{n}=952)$ & $539(56.6)$ & $1.23(0.99$ to 1.54$)$ & $1.17(0.94$ to 1.47$)$ & $1.25(1.05$ to 1.50$)$ \\
\hline Hungry in last month (lack of money) & $99(10.4)$ & 1.61 (1.23 to 2.11$)$ & $1.59(1.20$ to 2.11$)$ & 1.34 (1.06 to 1.70$)$ \\
\hline Indebted & $77(8.1)$ & 1.69 (1.26 to 2.25$)$ & $1.52(1.10$ to 2.09$)$ & 1.37 (1.06 to 1.77$)$ \\
\hline No emergency resources $(n=952)$ & $595(62.5)$ & $0.98(0.79$ to 1.23$)$ & $0.87(0.69$ to 1.08$)$ & $1.06(0.88$ to 1.27$)$ \\
\hline \multicolumn{5}{|l|}{ Environment } \\
\hline Urban kebele & $135(14.2)$ & $0.87(0.62$ to 1.20$)$ & $0.71(0.49$ to 1.03$)$ & $0.75(0.56$ to 1.01$)$ \\
\hline \multicolumn{5}{|l|}{ Other children $<5$ years } \\
\hline None & $196(20.6)$ & Reference & Reference & Reference \\
\hline 1 Child $<5$ years & $485(50.8)$ & $1.61(1.16$ to 2.22$)$ & $1.17(0.87$ to 1.56$)$ & $0.77(0.63$ to 0.96$)$ \\
\hline 2 Or more children & $273(28.6)$ & $1.38(0.96$ to 1.97$)$ & $0.92(0.66$ to 1.29$)$ & $0.88(0.70$ to 1.10$)$ \\
\hline Unprotected water supply ( $\mathrm{n=952)}$ & $287(30.2)$ & $0.97(0.77$ to 1.23$)$ & $0.93(0.73$ to 1.18$)$ & $0.96(0.80$ to 1.16$)$ \\
\hline No latrine & $354(37.1)$ & $1.16(0.94$ to 1.45$)$ & $1.15(0.92$ to 1.43$)$ & $0.97(0.81$ to 1.16$)$ \\
\hline Rubbish disposed on fields ( $n=953$ ) & 742 (77.9) & $1.02(0.79$ to 1.33$)$ & $1.07(0.81$ to 1.40$)$ & $1.00(0.81$ to 1.23$)$ \\
\hline Animals in house $(n=953)$ & $598(62.8)$ & $1.37(1.08$ to 1.74$)$ & $1.15(0.92$ to 1.43$)$ & 1.18 (0.98 to 1.42$)$ \\
\hline No window $(\mathrm{n}=953)$ & $593(62.2)$ & $1.19(0.94$ to 1.49$)$ & $1.18(0.93$ to 1.49$)$ & $1.09(0.91$ to 1.30$)$ \\
\hline \multicolumn{5}{|l|}{ Maternal ill-health } \\
\hline Fever since birth & $240(25.2)$ & $1.58(1.27$ to 1.96$)$ & 1.51 (1.20 to 1.89$)$ & $1.60(1.35$ to 1.89$)$ \\
\hline Malaria since birth $(n=949)$ & $125(13.2)$ & $1.39(1.06$ to 1.82$)$ & $1.45(1.11$ to 1.91$)$ & $1.33(1.07$ to 1.65$)$ \\
\hline Diarrhoea since birth & $55(5.8)$ & $1.67(1.20$ to 2.33$)$ & $1.34(0.90$ to 1.99$)$ & $1.49(1.13$ to 1.96$)$ \\
\hline BMI $\left(\mathrm{kg} / \mathrm{m}^{2}\right)(\mathrm{n}=765)$ & $146(19.1)$ & $0.95(0.90$ to 1.00$)$ & $0.78(0.55$ to 1.11$)$ & $0.98(0.76$ to 1.26$)$ \\
\hline \multicolumn{5}{|l|}{ Maternal substance use } \\
\hline Alcohol use ( $\geq$ weekly) & $17(1.8)$ & $1.37(0.71$ to 2.63$)$ & $0.47(0.13$ to 1.73$)$ & $0.67(0.28$ to 1.58$)$ \\
\hline Khat use ( $\geq$ weekly) & $95(10.0)$ & $1.06(0.75$ to 1.50$)$ & $1.06(0.74$ to 1.52$)$ & $0.92(0.68$ to 1.25$)$ \\
\hline \multicolumn{5}{|l|}{ Infant characteristics } \\
\hline \multicolumn{5}{|l|}{ Birth weight } \\
\hline Normal & $468(49.1)$ & Reference & Reference & Reference \\
\hline Low $(<2500 \mathrm{~g})$ & $35(3.7)$ & $0.96(0.54$ to 1.72$)$ & $0.96(0.54$ to 1.72$)$ & $1.28(0.88$ to 1.88$)$ \\
\hline Not measured & $451(47.3)$ & $1.05(0.84$ to 1.30$)$ & $0.86(0.69$ to 1.08$)$ & $0.94(0.79$ to 1.13$)$ \\
\hline Female infant & $469(49.2)$ & $0.97(0.78$ to 1.20$)$ & $0.82(0.65$ to 1.02$)$ & $0.86(0.72$ to 1.02$)$ \\
\hline \multicolumn{5}{|l|}{ Lack of social support } \\
\hline Low frequency of contact with friends & $144(15.1)$ & $1.15(0.87$ to 1.52$)$ & $1.07(0.79$ to 1.44$)$ & $1.13(0.90$ to 1.42$)$ \\
\hline Can't rely on family & $189(19.8)$ & $1.02(0.78$ to 1.33$)$ & $1.00(0.76$ to 1.31$)$ & $1.05(0.85$ to 1.30$)$ \\
\hline Not enough help at home $(n=953)$ & $366(38.4)$ & $0.84(0.67$ to 1.05$)$ & $0.94(0.75$ to 1.18$)$ & $0.82(0.68$ to 0.98$)$ \\
\hline Not enough help with children & $426(44.7)$ & $0.87(0.70$ to 1.08$)$ & $0.91(0.73$ to 1.14$)$ & $0.87(0.73$ to 1.04$)$ \\
\hline Not enough help from husband $(n=943)$ & $93(9.9)$ & $1.18(0.85$ to 1.64$)$ & $1.04(0.73$ to 1.50$)$ & $1.16(0.89$ to 1.51$)$ \\
\hline \multicolumn{5}{|l|}{ Potential mediators } \\
\hline Breast feeding delayed $\geq 8 \mathrm{~h}(\mathrm{n}=939)$ & $65(6.9)$ & 1.41 (0.99 to 1.99$)$ & $1.05(0.69$ to 1.60$)$ & $1.50(1.16$ to 1.94$)$ \\
\hline Non-exclusive breast feeding & $152(15.9)$ & $0.93(0.68$ to 1.25$)$ & $0.97(0.72$ to 1.32$)$ & $1.08(0.86$ to 1.36$)$ \\
\hline Soap use < daily & $401(42.0)$ & $1.40(1.13$ to 1.73$)$ & $1.15(0.92$ to 1.43$)$ & $1.19(1.00$ to 1.41$)$ \\
\hline No vaccinations $(n=951)$ & $221(23.2)$ & $1.12(0.88$ to 1.43$)$ & $1.16(0.91$ to 1.49$)$ & $1.18(0.97$ to 1.42$)$ \\
\hline Maternal functioning impaired $\geq 15$ days & $75(7.9)$ & $1.20(0.84$ to 1.71$)$ & 1.50 (1.08 to 2.07$)$ & $1.20(0.90$ to 1.59$)$ \\
\hline
\end{tabular}

$\mathrm{n}=954$ singleton mother-infant pairs

$\mathrm{ARI}$, acute respiratory illness; BMI, body mass index.

maternal BMI, an objective indicator of maternal health status, strengthened the observed association. Moreover, when selfreported maternal ill-health was excluded from the adjusted model including BMI, CMD symptoms occurring in the postnatal period only became significantly associated with infant diarrhoea (RR 1.96; 95\% CI 1.10 to 3.51).

In this analysis, maternal ill-health was conceptualised as a potential confounder of the relationship between maternal $\mathrm{CMD}$ and infant illness episodes, but could also have mediated the relationship. Symptoms of CMD might increase the mother's own risk of contracting an infectious illness and thereby lead to infant ill-health, either through exposure to the mother's pathogens or by further interfering with optimal infant care.

Maternal CMD was not associated with infant fever or ARI after adjusting for confounders. This is in keeping with the study from Pakistan ${ }^{23}$ but contradicts the findings from Nigeria. ${ }^{18}$ However, the latter study was clinic-based, did not specify which illnesses were being considered and did not control for confounders. Our finding of a differential effect of maternal CMD symptoms on risk of different infant illnesses is not altogether unexpected. The risk of developing ARI is strongly influenced by indoor air pollution and crowding, in addition to maternal health behaviours. ${ }^{35}$ Likewise, the risk 
Table 2 RR for association between high levels of CMD symptoms (SRO $\geq 6$ ) and infant diarrhoea (with robust standard errors)

\begin{tabular}{|c|c|c|c|}
\hline \multirow[b]{2}{*}{ Maternal CMD and infant diarrhoea } & \multicolumn{3}{|l|}{ RR $(95 \%$ Cl) } \\
\hline & SR0 $\geq 6$, pregnancy only & SR0 $\geq 6$, postnatal only & SR0 $\geq 6$, persistent \\
\hline Crude RR ( $n=954)$ & $0.98(0.66$ to 1.44$)$ & 1.84 (1.12 to 3.03$)$ & $2.90(2.18$ to 3.85$)$ \\
\hline \multicolumn{4}{|l|}{ (1) Adjusted separately for } \\
\hline Maternal characteristics $(n=947)$ & $0.99(0.67$ to 1.46$)$ & 1.79 (1.09 to 2.93$)$ & 2.81 (2.06 to 3.83$)$ \\
\hline Parental education $(\mathrm{n}=947)$ & $1.00(0.68$ to 1.48$)$ & 1.84 (1.11 to 3.03$)$ & 2.92 (2.18 to 3.92$)$ \\
\hline Socio-economic status $(n=944)$ & 0.95 (0.64 to 1.39 ) & 1.47 (0.87 to 2.48$)$ & 2.38 (1.69 to 3.36$)$ \\
\hline Environmental conditions $(n=950$ ) & $0.96(0.65$ to 1.41$)$ & $1.65(1.01$ to 2.70$)$ & 2.71 (2.02 to 3.64$)$ \\
\hline Maternal ill-health $(n=950)$ & $0.97(0.65$ to 1.44$)$ & 1.41 (0.80 to 2.48$)$ & 2.33 (1.67 to 3.26$)$ \\
\hline Maternal substance use $(\mathrm{n}=955)$ & $0.98(0.66$ to 1.45$)$ & $1.86(1.13$ to 3.07$)$ & 2.93 (2.20 to 3.89 ) \\
\hline Infant characteristics $(\mathrm{n}=955)$ & $0.97(0.66$ to 1.43$)$ & $1.83(1.10$ to 3.03$)$ & $2.97(2.22$ to 3.98$)$ \\
\hline Social support $(n=943)$ & $0.95(0.64$ to 1.43$)$ & $1.86(1.11$ to 3.10$)$ & 2.82 (2.07 to 3.85$)$ \\
\hline \multicolumn{4}{|l|}{ (2) Fully adjusted models } \\
\hline Model $A$ ( $n=925$ ): fully adjusted (excluding BMI) & $0.93(0.63$ to 1.37$)$ & 1.15 (0.65 to 2.04$)$ & $2.15(1.39$ to 3.34$)$ \\
\hline Model A+BMI $(n=748)$ & $1.06(0.66$ to 1.72$)$ & $1.66(0.85$ to 3.21$)$ & $2.34(1.50$ to 3.65$)$ \\
\hline \multicolumn{4}{|l|}{ (3) Testing for mediators } \\
\hline Model $A+$ delayed breast feeding $(n=910)$ & $0.93(0.63$ to 1.37$)$ & 1.18 (0.67 to 2.09$)$ & 2.09 (1.35 to 3.24$)$ \\
\hline Model $A+$ non-exclusive breast feeding $(n=925)$ & $0.93(0.63$ to 1.38$)$ & $1.16(0.65$ to 2.06$)$ & $2.19(1.41$ to 3.40$)$ \\
\hline Model $A+$ soap use $(n=925)$ & 0.92 (0.62 to 1.36$)$ & $1.13(0.63$ to 2.01$)$ & $2.13(1.37$ to 3.29$)$ \\
\hline Model A+vaccination status $(n=922)$ & 0.91 (0.62 to 1.33$)$ & $1.13(0.64$ to 1.99$)$ & $2.16(1.40$ to 3.33$)$ \\
\hline Model $A+$ maternal disability $(n=925)$ & $0.93(0.63$ to 1.37$)$ & $1.20(0.67$ to 2.14$)$ & $2.29(1.45$ to 3.61$)$ \\
\hline
\end{tabular}

Infant diarrhoea (with robust standard errors) adjusting for (1) groups of confounders separately, (2) all confounders simultaneously and (3) with addition of possible mediators to the fully adjusted model.

$\mathrm{BMI}$, body mass index; CMD, common mental disorder; SRO, Self-Reporting Questionnaire.

Table 3 Multivariable analysis of association between high levels of maternal CMD symptoms (SRO $\geq 6)$ and infant acute respiratory illness and febrile illness (with robust standard errors)

\begin{tabular}{|c|c|c|c|}
\hline \multirow[b]{2}{*}{ Maternal CMD and infant ARI } & \multicolumn{3}{|l|}{ RR $(95 \%$ CI) } \\
\hline & SR0 $\geq 6$, pregnancy only & SRO $\geq 6$, postnatal only & SRO $\geq 6$, persistent \\
\hline Crude RR $(n=954)$ & $1.03(0.70$ to 1.51$)$ & $0.83(0.34$ to 2.00$)$ & $2.24(1.52$ to 3.30$)$ \\
\hline Fully adjusted model (excluding BMI) $(\mathrm{n}=925)$ & $1.09(0.74$ to 1.59$)$ & $0.57(0.24$ to 1.40$)$ & $1.50(0.93$ to 2.41$)$ \\
\hline Fully adjusted model+BMI $(n=748)$ & $1.17(0.73$ to 1.88$)$ & $0.57(0.20$ to 1.65$)$ & $1.47(0.92$ to 2.34$)$ \\
\hline \multicolumn{4}{|l|}{ Maternal CMD and infant fever } \\
\hline Crude RR $(n=954)$ & $1.18(0.90$ to 1.55$)$ & $1.48(0.95$ to 2.32$)$ & $1.61(1.10$ to 2.35$)$ \\
\hline Fully adjusted model (excluding BMI) $(n=925)$ & $1.08(0.80$ to 1.45$)$ & 0.99 (0.63 to 1.57$)$ & $1.08(0.71$ to 1.65$)$ \\
\hline Fully adjusted model+BMI $(n=748)$ & $1.24(0.87$ to 1.75$)$ & $1.24(0.74$ to 2.10$)$ & $0.99(0.62$ to 1.56$)$ \\
\hline
\end{tabular}

ARI, acute respiratory illness; BMI, body mass index; CMD, common mental disorder; SRQ, Self-Reporting Questionnaire.

of fever is influenced by a broad spectrum of factors, ranging from cramped living conditions facilitating transmission, to exposure to insect bites and poor hygiene practices. Infant diarrhoea, on the other hand, is influenced predominantly by non-exclusive breast feeding, ${ }^{36}$ poor hygiene practices ${ }^{37} 38$ and poor sanitation, ${ }^{39} 40$ which, in this setting, are largely dependent upon the mother's actions.

Relying on maternal self-report could have resulted in misclassification of infant illness status. However, any such misclassification is likely to have been non-differential. Although negative recall bias could have led women with postnatal CMD to over-report infant illness, the importance of the "persistent CMD' exposure makes this less likely as persistent $\mathrm{CMD}$ incorporates CMD measured before the commencement of the postnatal period.

In previous studies from LAMICs, postnatal CMD was associated with early cessation of breast feeding, ${ }^{16}$ decreased vaccination $^{17}$ and impaired mother-infant relationship, ${ }^{10}$ all of which could mediate an effect of maternal CMD on infant illness. However, in this study, there was no evidence that delayed initiation of breast feeding, non-exclusive breast feeding, infrequent soap use, overdue infant vaccination or impaired maternal functioning mediated the association between persistent perinatal CMD and infant illness. There are a number of possible explanations for this negative finding. Aside from the BCG vaccination, the recommended age for first infant vaccination is 6 weeks, with full protection not afforded until completion of the entire course. Therefore, at 2 months after birth, vaccination status may have explained little variation in risk of infant illness, limiting our ability to find an association. Our reliance on self-report of maternal hygiene practices could have led to social desirability bias; direct observation of maternal behaviour would have been preferable. ${ }^{41}$ Other unmeasured hygiene practices associated with increased risk of infant diarrhoea, such as method of handling infant faeces and hand-washing after defecating, ${ }^{38}$ might also have been relevant in this population.

Our study indicates that impaired maternal health behaviours do not adequately explain the relationship between maternal CMD and infant ill-health. Recent intervention studies from LAMICs suggest an alternative hypothesis: a direct effect of the mother-infant relationship. Maternal CMD is associated with more intrusive and less sensitive motherinfant interactions and subsequent insecure attachment. ${ }^{42}$ In Pakistan, a successful community-based psychological intervention for depressed mothers led to increased time spent in play-related activity as well as a decrease in infant diarrhoeal episodes, underscoring the importance of mother-infant 
interactions. ${ }^{43}$ In South Africa, interventions from trained lay workers improved the mother-infant relationship, reduced maternal depressive symptoms and decreased insecure attachment. ${ }^{44}$ Such studies demonstrate the feasibility of intervention and could shed further light on mechanisms linking maternal CMD and infant ill-health.

\section{CONCLUSION}

This is the first prospective population-based study from subSaharan Africa to investigate the association between maternal CMD and infant illness. Perinatal CMD increased risk of infant diarrhoea, but not fever or ARI. More research is needed to identify mechanisms underlying the association, particularly examining the role of the mother-infant relationship. Meanwhile women's health services and integrated management of childhood illness programmes should consider women's mental health during the perinatal period and learn from recent successful intervention studies from LAMICs.

Acknowledgements The authors wish to express their thanks to the women who participated in the study for generously giving their time and energy to complete interviews, and to the staff of the BRHP for their kind co-operation. The authors are also grateful to Unicef for providing scales for the anthropometric measurements.

Funding The Wellcome Trust provided funding for this study (GR07164A) Competing interests None.

Ethics approval This study was conducted with the approval of the Ethiopian Science and Technology Agency (National Research Ethics Committee) and King's College London Research Ethics Committee.

Provenance and peer review Not commissioned; externally peer reviewed.

\section{REFERENCES}

1. Murray L, Cooper PJ. Postpartum depression and child development. Psychol Med 1997;27:253-60.

2. Murray L, Sinclair D, Cooper P, et al. The socioemotional development of 5-year-old children of postnatally depressed mothers. J Child Psychol Psychiatry 1999;40:1259-71.

3. Hay DF, Pawlby S, Sharp D, et al. Intellectual problems shown by 11-year-old children whose mothers had postnatal depression. J Child Psychol Psychiatry 2001:42:871-89.

4. Leiferman $\mathbf{J}$. The effect of maternal depressive symptomatology on maternal behaviors associated with child health. Health Educ Behav 2002;29:596-607.

5. Guttmann A, Dick P, To T. Infant hospitalization and maternal depression, poverty and single parenthood - a population-based study. Child Care Health Dev 2004:30:67-75

6. MandI KD, Tronick EZ, Brennan TA, et al. Infant health care use and maternal depression. Arch Pediatr Adolesc Med 1999;153:808-13.

7. Minkovitz CS, Strobino D, Scharfstein D, et al. Maternal depressive symptoms and children's receipt of health care in the first 3 years of life. Pediatrics 2005;115:306-14

8. Halbreich U, Karkun S. Cross-cultural and social diversity of prevalence of postpartum depression and depressive symptoms. J Affect Disord 2006;91:97-111.

9. Nakku JE, Nakasi G, Mirembe F. Postpartum major depression at six weeks in primary health care: prevalence and associated factors. Afr Health $\mathrm{SCi}$ 2006:6:207-14.

10. Cooper PJ, Tomlinson M, Swartz L, et al. Post-partum depression and the mother-infant relationship in a South African peri-urban settlement. $\mathrm{Br} J$ Psychiatry 1999;175:554-8.

11. Rahman A, Bunn J, Lovel H, et al. Association between antenatal depression and low birthweight in a developing country. Acta Psychiatr Scand 2007;115:481-6.

12. Patel V, Prince M. Maternal psychological morbidity and low birth weight in India. Br J Psychiatry 2006:188:284-5.

13. Ferri CP, Mitsuhiro SS, Barros MC, et al. The impact of maternal experience of violence and common mental disorders on neonatal outcomes: a survey of adolescent mothers in Sao Paulo, Brazil. BMC Public Health 2007;7:209.

14. Hanlon C, Medhin G, Alem A, et al. Impact of antenatal common menta disorders upon perinatal outcomes in Ethiopia: the P-MaMiE population-based cohort study. Trop Med Int Health 2009:14:156-66.
15. Anoop S, Saravanan B, Joseph A, et al. Maternal depression and low maternal intelligence as risk factors for malnutrition in children: a community based casecontrol study from South India. Arch Dis Child 2004;89:325-9.

16. Patel V, DeSouza N, Rodrigues M. Postnatal depression and infant growth and development in low income countries: a cohort study from Goa, India. Arch Dis Child 2003;88:34-7.

17. Rahman A, Iqbal Z, Bunn J, et al. Impact of maternal depression on infant nutritional status and illness: a cohort study. Arch Gen Psychiatry 2004;61:946-52.

18. Adewuya A0, Ola B0, Aloba 00 , et al. Impact of postnatal depression on infants growth in Nigeria. J Affect Disord 2008;108:191-3.

19. Stewart RC, Umar E, Kauye F, et al. Maternal common mental disorder and infant growth-a cross-sectional study from Malawi. Matern Child Nutr 2008;4:209-19.

20. Baker-Henningham H, Powell C, Walker S, et al. Mothers of undernourished Jamaican children have poorer psychosocial functioning and this is associated with stimulation provided in the home. Eur J Clin Nutr 2003;57:786-92.

21. Howe LD, Huttly SR, Abramsky T. Risk factors for injuries in young children in four developing countries: the Young Lives Study. Trop Med Int Health 2006;11:1557-66.

22. Humphreys D, Araya M, Cruchet $\mathrm{S}$, et al. Maternal neurotic symptoms and infants' risk of developing persistent diarrhoea. Rev Saude Publica 1996;30:213-17

23. Rahman A, Bunn J, Lovel H, et al. Maternal depression increases infant risk of diarrhoeal illness: a cohort study. Arch Dis Child 2007;92:24-8.

24. Rahman A, Harrington R, Bunn J. Can maternal depression increase infant risk of illness and growth impairment in developing countries? Child Care Health Dev 2002;28:51-6

25. Berhane Y, Wall S, Kebede D, et al. Establishing an epidemiological field laboratory in rural areas - potentials for public health research and interventions. The Butajira Rural Health Programme 1987-99. (Special Issue). EJHD; 1999:13;1-47.

26. Central Statistical Authority (Ethiopia) and ORC Macro. Ethiopia demographic and health survey 2005. Addis Ababa, Ethiopia, and Calverton, Maryland, USA: Central Statistical Authority and ORC Macro, 2006.

27. WHO Division of Mental Health. A user's guide to the Self-Reporting Questionnaire (SRO). Geneva: WHO, 1994.

28. Hanlon C, Medhin G, Alem A, et al. Detecting perinatal common mental disorder in Ethiopia: validation of the self-reporting questionnaire and Edinburgh Postnatal Depression Scale. J Affect Disord 2008;108:251-62.

29. Cox JL, Connor Y, Kendell RE. Prospective study of the psychiatric disorders of childbirth. Br J Psychiatry 1982;140:111-17.

30. WHO Expert Committee. Physical status: the use and interpretation of anthropometry. Geneva: WHO, 1995.

31. WHO. World Health Organization Disability Assessment Schedule II. 12 item interviewer-administered version. Geneva: WHO, 2000

32. Mogga S, Prince M, Alem A, et al. Outcome of major depression in Ethiopia: population-based study. Br J Psychiatry 2006;189:241-6.

33. Lumley T, Kronmal R, Ma S. Relative risk regression in medical research: models, contrasts, estimators and algorithms. Washington, DC, USA: University of Washington, 2006.

34. StataCorp. Stata/SE Version 10.1. Texas, USA: StataCorp, 2008.

35. Rabie T, Curtis V. Handwashing and risk of respiratory infections: a quantitative systematic review. Trop Med Int Health 2006;11:258-67.

36. Huffman SL, Combest C. Role of breast-feeding in the prevention and treatment of diarrhoea. J Diarrhoeal Dis Res 1990;8:68-81.

37. Ghosh S, Sengupta PG, Mondal SK, et al. Risk behavioural practices of rural mothers as determinants of childhood diarrhoea. J Commun Dis 1997;29:7-14.

38. Curtis V, Cairncross S. Effect of washing hands with soap on diarrhoea risk in the community: a systematic review. Lancet Infect Dis 2003;3:275-81.

39. Genser B, Strina A, Teles CA, et al. Risk factors for childhood diarrhea incidence: dynamic analysis of a longitudinal study. Epidemiology 2006;17:658-67.

40. Huttly S, Morris S, Pisani V. Prevention of diarrhoea in young children in developing countries. Bull World Health Organ 1997:75:163-74.

41. Ruel M, Arimond M. Measuring childcare practices: approaches, indicators, and implications for programs. Washington, DC, USA: International Food Policy Research Institute, 2003.

42. Tomlinson $\mathbf{M}$, Cooper P, Murray L. The mother-infant relationship and infant attachment in a South African peri-urban settlement. Child Dev 2005;76:1044-54.

43. Rahman A, Malik A, Sikander S, et al. Cognitive behaviour therapy-based intervention by community health workers for mothers with depression and their infants in rural Pakistan: a cluster-randomised controlled trial. Lancet 2008;372:902-9.

44. Cooper PJ, Tomlinson M, Swartz L, et al. Improving quality of mother-infant relationship and infant attachment in socioeconomically deprived community in South Africa: randomised controlled trial. BMJ 2009;338:b974. 